Brit. J. soc. Med. (1947), 1, 51-72.

\title{
A STUDY OF THE HAEMATOLOGY OF 663 SUBSTANDARD RECRUITS UNDER TRAINING AT AN ARMY PHYSICAL DEVELOPMENT CENTRE
}

\author{
BY \\ R. A. M. CASE, M.B., Ch.B., Ph.D. \\ From the Department of Pathology, The University of Birmingham, and the Royal Naval \\ Physiological Laboratory
}

(Received April 1, 1946)

It has been the general experience of the authorities concerned, whether medical officers or not, that there is a dramatic improvement in health, physique, performance, and morale of substandard recruits who undergo a course of training at a Physical Development Centre (P.D.C.), but until recently there has been little information available about the biological criteria affected by this improvement.

During the years 1944 and 1945 an extensive piece of field research was carried out at No. 1 P.D.C., Bradbury Lines, Hereford, by the Army Department of Physical Medicine and the Army Department of Medical (Statistical) Research into the changes produced by the course of training, with a view to the correlation and evaluation of the factors involved, both physical and psychological. An immense amount of data was collected and submitted to analysis, and it is to be presumed that a comprehensive report will be published at some time, but a discussion of the general findings is outside the scope of this paper.

The haematological findings in themselves, however, provide an extremely interesting field for analysis and speculation, and this communication is confined solely to this aspect of the investigation.

It is widely recognized that group haemoglobin levels are useful criteria of general nutrition and well-being, and it appears to be tacitly assumed, even if not explicitly stated, that the higher the mean value the more satisfactory is the state of affairs. As will be shown later, this work affords some reason to doubt the validity of this assumption.

A further criterion which might prove of value in such survey work is the siderocyte level, normal values having been recently established by Case, Ladan, and Nutt (1945) for both males and females of varying age groups. The siderocyte, as an index of the number of effete erythrocytes (Case, 1943, 1945b, 1945c) should prove useful in elucidating the mechanism of any low haemoglobin values found. 


\section{MethodS AND MATERIALS}

In all, 663 recruits between the ages of 17 and 20 were examined on arrival at Bradbury Lines and eight weeks later when due to pass out of the station. These 663 men were the complement of three companies, of 194, 232, and 237 recruits. These figures refer to the passing-out strength, and the few who became casualties during the course, generally for traumatic reasons, are not included at all in the figures given. Of these entrants, all of whom were referred to the Centre because of " poor physique," over $80 \%$ passed out in the first grade. The term " poor physique " is almost undefinable, being a clinical opinion often compounded of several imponderables, though a careful attempt at analysing the picture was made by my colleagues when the draft arrived. The selection of the candidates was made, in two companies, by the medical officers to the units to which the recruit was drafted after conscription, and in the third company by the civilian recruitment medical board. Thus two companies were not only selected by a different process but had had approximately two more weeks' Army training and food. This may be of some significance, for, as will be shown later, two companies were drawn from exactly the same haematological " universe," whilst the third company, drafted straight from civilian life, differed very materially in haematological criteria. Nevertheless, for most of the statistical analysis, it has been considered fairer to compound all three companies into one body.

A discussion of the training at the P.D.C. is out of place in this paper, but, broadly speaking, it consisted in graded physical exercise, marches, rest periods, and adequate feeding. An analysis of the food provided in the mess (i.e., after preparation) was carried out by Dr. Robert Gaddie, of the General Hospital, Birmingham, and it was found to be very satisfactory from a calorific, vitamin, and mineral aspect. The palatability was attested by the recruits themselves, some slight monotony being almost the only criticism.

The scope of the haematological examination was as follows: (a) Haemoglobin estimations, before and after course; $(b)$ siderocyte counts, before and after course. These were performed on all entrants. (c) Examination of stained films in all entrants whose initial haemoglobin fell below the arbitrary figure of $86 \%(100 \%=$ 14.8 grams of $\mathrm{Hb} \%$ ) before and after course. In this examination, attention was directed to anisocytosis, poikilocytosis, microcytosis, macrocytosis, and hypochromicity. (d) A full blood count (erythrocytes and differential leucocyte count) was performed on all recruits whose initial haemoglobin level fell below $75 \%$. Those whose initial haemoglobin was below $86 \%$ were called " anaemics" and will be discussed later in a separate section.

The haemoglobin estimations were carried out by the alkaline haematin method of Clegg and King (1942), the alkalinized solution being evaluated on a " Spekker" photoelectric absorptiometer using an llford " 604 " spectral green filter and $1 \mathrm{~cm}$. cells. The standard error of estimate was $\pm 2 \%$. 


\section{Technique of Hb Estimation}

The exact technique was as follows: The middle finger of the left hand was cleaned with a cotton-wool swab moistened with ether. A tourniquet of $\frac{3}{16}$ in. rubber tubing was applied proximal to the distal phalanx, and a prick made to one side of the nail with a chisel-pointed automatic needle. (This needle was re-sharpened daily.) The tourniquet was at once released and the first small drop of blood was used to make two thin blood films on clear numbered slides. The tourniquet was again applied and a bead of blood allowed to appear. This was sucked to the mark in a $0.075-\mathrm{ml}$. pipette attached to $5 \mathrm{in}$. of $\frac{1}{8}$-in. rubber tubing fitted with a glass mouthpiece. This long length of tubing is a great convenience, as it allows the operator considerable freedom of movement. The end of the pipette was wiped on cotton-wool, the level adjusted to the mark (if necessary), and the blood blown into $7.5 \mathrm{ml}$. of $\mathrm{N} / 10 \mathrm{NaOH}$ solution previously placed in a boiling tube, and the alkali sucked up and down. The pipette was then removed from the tube and placed on the bench. An assistant, who was seated behind the operator and had recorded the subject's name and laboratory serial number during these proceedings, at once seized the pipette and washed it on a suction pump with water, alcohol, and ether. The whole speed of the process depends upon this assistant, and it was found possible, using only two pipettes, to alkalinize over 100 blood specimens in two 2-hour sessions on the same day.

The boiling tubes were charged with alkali before the session began, using alternately two 7.5-ml. automatic pipettes. The alkalinized blood was evaluated by the assistant, and the results read from a graph, originally calibrated with alkaline haematin made from pure haemin, checked by 40 oxygen capacity measurements made by the method of van Slyke and Neill (1924) and rechecked at Hereford against a sample of alkaline haematin supplied by Dr. E. J. King. No adjustment of the original calibration was found to be necessary.

The absorptiometer cups were filled by pipette and emptied in situ by a fine tube attached to the suction pump, no attempt to wash them between estimations being made, as the trace of alkalinized blood left in would cause less error than a similar amount of water, and to wash and dry between each estimation was quite impracticable.

The possibility of error arising from such factors as engorgement due to the tourniquet or cold hands was considered, and a series of control experiments showed that variations due to these causes could be ignored.

Diurnal variation was as far as possible eliminated by arranging the time-table in such a way that each section attended at the same hour on each sampling, and violent exercise before examination was avoided.

The alkaline haematin method was chosen because it is quick, reasonably accurate and free from subjective error. The Haldane-Gowers (1901) technique was ruled out because no gas supply was available, apart from any other consideration, but the results have been expressed in percentages on the B.S.I. Haldane scale $(100 \%=14.8$ grams $\mathrm{Hb} \%$ : Macfarlane and O'Brien, 1944; King, Gilchrist and Matheson, 1944) in order to make comparison with published data easy.

It should be stressed, however, that the primary object of this investigation was to assess the effects of training upon the subjects, not to compare the results with other series, so that the fact that the method used is not that used in the Haemoglobin Survey Committee's (M.R.C., 1945) investigations is not of great moment.

It would have been impossible to make the estimations in the time available by the Haldane-Gowers technique, and, as it was, variance from technical sources was reduced to a minimum by using only two carefully calibrated pipettes, one photometer cup, and one operator evaluating the alkalinized blood. 
Owing to the differences in technique employed, no statistical computations of the significance of differences of the haemoglobin values herein reported and the observations of other workers have been carried out, but such computations are justifiable in the case of the siderocyte levels, since not only was the technique the same but most of the counts were performed by the same observer.

The blood films were numbered with a diamond, dried in air, and fixed in methyl alcohol at the end of each session.

Films for siderocyte estimations were stained by the $\alpha \alpha^{1}$ dipyridyl-thiocyanate technique of Case (1944) and counterstained with $1 \%$ Biebrich scarlet. The slides were examined with a $2-\mathrm{mm}$. oil-immersion lens and a $\times 12$ ocular, and the siderocyte incidence estimated by counting 16 siderocytes and the distribution of nonsiderocyte erythrocytes around them. The incidence is then given by the equation $\mathrm{f} \%=\frac{\mathrm{m}-1}{\mathrm{n}} \times \frac{100}{1}$ where $\mathrm{f}$ is the frequency of the abnormal cell (siderocyte), $\mathrm{m}$ is the number of abnormals counted, and $\mathrm{n}$ is the number of normals counted during the observation. The mathematical justification for this procedure is fully discussed by Haldane (1945a, 1945b), and the method of sampling has become known as inverse binomial sampling (Tweedie, 1945; Case, 1945a). The method has the advantage of great accuracy when a small fraction of abnormals are present, and of a saving of time and labour when a large fraction exists.

The duplicate blood films from the " anaemics " were stained with Leishman's stain in the usual manner.

\section{RESULTS}

Table I shows the means, standard deviations, and coefficients of variation of the haemoglobin values for each company before and after training, and also for the whole 663 recruits. (These parameters are calculated from the ungrouped data.)

TABLE I

Haemoglobin levels (\%) in incoming and outgoing recruits

\begin{tabular}{|c|c|c|c|c|c|c|c|c|c|c|}
\hline \multirow{2}{*}{. } & & & & \multicolumn{4}{|c|}{ Incoming } & \multicolumn{3}{|c|}{ Outgoing } \\
\hline & & & & $\mathbf{n}$ & Mean & $\sigma$ & v & Mean & $\sigma$ & v \\
\hline $\begin{array}{l}\text { 1st coy. } \\
\text { 2nd coy. } \\
\text { 3rd coy } \\
\text { Whole group }\end{array}$ & $\begin{array}{l}. \\
. \\
\ldots\end{array}$ & $\begin{array}{l}. . \\
. \\
.\end{array}$ & $\begin{array}{l}. . \\
\ldots \\
.\end{array}$ & $\begin{array}{l}194 \\
237 \\
232 \\
663\end{array}$ & $\begin{array}{l}92 \cdot 88 \\
90 \cdot 73 \\
99 \cdot 75 \\
94 \cdot 52\end{array}$ & $\begin{array}{c}11 \cdot 77 \\
7 \cdot 68 \\
9 \cdot 1 \\
9 \cdot 49\end{array}$ & $\begin{array}{r}12.7 \% \\
8.5 \% \\
9.1 \% \\
10.0 \%\end{array}$ & $\begin{array}{l}99 \cdot 91 \\
98 \cdot 68 \\
97 \cdot 78 \\
98 \cdot 72\end{array}$ & $\begin{array}{l}7 \cdot 91 \\
6 \cdot 78 \\
7 \cdot 31 \\
7 \cdot 31\end{array}$ & $\begin{array}{l}7.9 \% \\
6.9 \% \\
7.5 \% \\
7.40\end{array}$ \\
\hline
\end{tabular}


Table II shows the corresponding parameters for the siderocyte levels.

TABLE II

Siderocyte levels (per 1,000) in incoming and outgoing recruits

\begin{tabular}{|c|c|c|c|c|c|c|c|c|c|c|}
\hline & & & & \multicolumn{4}{|c|}{ Incoming } & \multicolumn{3}{|c|}{ Outgoing } \\
\hline & & & & $\mathrm{n}$ & Mean & $\sigma$ & V & Mean & $\sigma$ & $\mathbf{V}$ \\
\hline $\begin{array}{l}\text { 1st coy. } \\
\text { 2nd coy. } \\
\text { 3rd coy. } \\
\text { Whole group }\end{array}$ & $\begin{array}{l}. . \\
\cdots \\
\cdots\end{array}$ & $\begin{array}{l}\cdots \\
\cdots \\
\cdots\end{array}$ & $\begin{array}{l}. \\
\because \\
\because\end{array}$ & \begin{tabular}{|l|}
194 \\
237 \\
232 \\
663
\end{tabular} & $\begin{array}{l}8 \cdot 8 \\
8 \cdot 4 \\
6 \cdot 3 \\
7 \cdot 8\end{array}$ & $\begin{array}{l}3 \cdot 9 \\
2 \cdot 9 \\
1 \cdot 9 \\
3 \cdot 0\end{array}$ & $\begin{array}{l}44.3 \% \\
34.9 \% \\
31.4 \% \\
38.1 \%\end{array}$ & $\begin{array}{l}4 \cdot 6 \\
4 \cdot 5 \\
5 \cdot 0 \\
4 \cdot 7\end{array}$ & $\begin{array}{l}2 \cdot 1 \\
1 \cdot 8 \\
2 \cdot 0 \\
2 \cdot 0\end{array}$ & $\begin{array}{l}45.3 \% \\
40.6 \% \\
40.4 \% \\
41.8 \%\end{array}$ \\
\hline
\end{tabular}

Computations of the significance of the difference of the means before and after training were carried out, "Student's" (1908) " $t$ " test being employed, and the " $t$ " values and approximate probabilities are shown in Table III.

TABLE III

Difference and significance of difference of outgoing from incoming means of haemoglobin and siderocyte levels

\begin{tabular}{|c|c|c|c|c|c|c|c|c|c|}
\hline & & & & \multicolumn{3}{|c|}{ Haemoglobin } & \multicolumn{3}{|c|}{ Siderocytes } \\
\hline & & & & Diff. & $t$ & $\mathbf{P}$ & Diff. & $\mathbf{t}$ & $\mathbf{P}$ \\
\hline $\begin{array}{l}\text { 1st coy. } \\
\text { 2nd coy. } \\
\text { 3rd coy. } \\
\text { Whole group }\end{array}$ & $\begin{array}{l}\cdots \\
\cdots \\
\cdots \\
\cdots\end{array}$ & $\begin{array}{l}\ldots \\
\cdots \\
\cdots \\
\cdots\end{array}$ & $\begin{array}{l}\cdots \\
\cdots \\
. \\
.\end{array}$ & $\begin{array}{l}+7.03 \\
+7.95 \\
-1.97 \\
+4.20\end{array}$ & $\begin{array}{c}6 \cdot 9 \\
12 \cdot 2 \\
2 \cdot 54 \\
8 \cdot 98\end{array}$ & $\begin{array}{r}0.001 \\
0.001 \\
0.011 \\
0.001\end{array}$ & $\begin{array}{l}-4 \cdot 2 \\
-3 \cdot 9 \\
-1 \cdot 3 \\
-3 \cdot 1\end{array}$ & $\begin{array}{c}13 \cdot 0 \\
17 \cdot 2 \\
6 \cdot 87 \\
22 \cdot 3\end{array}$ & $\begin{array}{l}0.001 \\
0.001 \\
0.001 \\
0.001\end{array}$ \\
\hline
\end{tabular}

Table IV analyses the difference and significance of difference of the coefficient of variation.

TABLE IV

Differences and significance of differences of $\mathrm{V}$ of the haemoglobin values

\begin{tabular}{|c|c|c|c|c|}
\hline & & Diff. & $\mathbf{t}$ & $\mathbf{P}$ \\
\hline $\begin{array}{l}\text { 1st coy. } \\
\text { 2nd coy. } \quad . \\
\text { 3rd coy. } \\
\text { Whole group }\end{array}$ & $\begin{array}{ll}\ldots & \ldots \\
\ldots & \ldots \\
\ldots & \cdots \\
\ldots & .\end{array}$ & $\begin{array}{l}4 \cdot 8 \\
1.6 \\
1.6 \\
2.6\end{array}$ & $\begin{array}{l}6 \cdot 27 \\
3 \cdot 20 \\
2 \cdot 92 \\
8 \cdot 29\end{array}$ & $\begin{array}{l}0.001 \\
0.0014 \\
0.0035 \\
0.001\end{array}$ \\
\hline
\end{tabular}

These tables show that, with the exception of the third company, there is a highly significant rise in the mean haemoglobin value, and, in all companies, an even more highly significant fall in the mean siderocyte level. Furthermore, a significant contraction of the coefficient of variation of the haemoglobin values 
TABLE V

Correlation table of haemoglobin and siderocyte levels of ingoing recruits

Siderocytes

$\mathrm{Hb} \% \quad 0-\quad 2-4-6-8-10-12-14-16-18-20-22-24-26-28-30-\begin{gathered}\text { Total } \\ \mathrm{F}_{1 \mathrm{i}}\end{gathered}$

\begin{tabular}{rrrrrrrrrrrrrrrrrrrr}
$122 \cdot 5-$ & 1 & 0 & 0 & 0 & 0 & 0 & 0 & 0 & 0 & 0 & 0 & 0 & 0 & 0 & 0 & 0 & 1 \\
$117 \cdot 5-$ & 1 & 0 & 1 & 2 & 0 & 0 & 0 & 0 & 0 & 0 & 0 & 0 & 0 & 0 & 0 & 0 & 4 \\
$112 \cdot 5-$ & 2 & 2 & 1 & 4 & 0 & 1 & 1 & 0 & 0 & 0 & 0 & 0 & 0 & 0 & 0 & 0 & 11 \\
$107 \cdot 5-$ & 1 & 6 & 6 & 18 & 5 & 1 & 1 & 1 & 1 & 0 & 0 & 0 & 0 & 0 & 0 & 0 & 39 \\
$102 \cdot 5-$ & 1 & 8 & 37 & 19 & 4 & 0 & 0 & 0 & 0 & 0 & 0 & 0 & 0 & 0 & 0 & 0 & 69 \\
$97 \cdot 5-$ & 0 & 4 & 68 & 32 & 9 & 4 & 0 & 0 & 1 & 0 & 0 & 0 & 0 & 0 & 0 & 0 & 118 \\
$92 \cdot 5-$ & 0 & 1 & 22 & 57 & 48 & 18 & 6 & 1 & 1 & 0 & 0 & 0 & 0 & 0 & 0 & 0 & 154 \\
$87 \cdot 5-$ & 1 & 1 & 5 & 18 & 46 & 43 & 11 & 5 & 1 & 0 & 0 & 0 & 0 & 0 & 0 & 0 & 131 \\
$82 \cdot 5-$ & 0 & 0 & 3 & 9 & 31 & 26 & 16 & 9 & 0 & 1 & 0 & 0 & 0 & 0 & 0 & 0 & 95 \\
$77 \cdot 5-$ & 0 & 1 & 1 & 6 & 7 & 2 & 0 & 4 & 1 & 1 & 0 & 0 & 0 & 0 & 0 & 0 & 23 \\
$72 \cdot 5-$ & 0 & 0 & 2 & 2 & 0 & 1 & 3 & 1 & 1 & 0 & 0 & 0 & 0 & 0 & 0 & 0 & 10 \\
$67 \cdot 5-$ & 0 & 0 & 0 & 0 & 0 & 1 & 1 & 0 & 0 & 0 & 1 & 0 & 0 & 0 & 0 & 0 & 3 \\
$62 \cdot 5-$ & 0 & 0 & 0 & 0 & 0 & 0 & 0 & 0 & 1 & 0 & 0 & 0 & 0 & 0 & 0 & 0 & 1 \\
$57 \cdot 5-$ & 0 & 0 & 0 & 0 & 0 & 1 & 0 & 0 & 0 & 0 & 0 & 0 & 0 & 0 & 0 & 0 & 1 \\
$52 \cdot 5-$ & 0 & 0 & 0 & 0 & 0 & 0 & 0 & 1 & 0 & 0 & 1 & 0 & 0 & 0 & 0 & 0 & 2 \\
$\mathbf{4 7} \cdot 5-$ & 0 & 0 & 0 & 0 & 0 & 0 & 0 & 0 & 0 & 0 & 0 & 0 & 0 & 0 & 0 & 0 & 0 \\
$\mathbf{4 2 \cdot 5 -}$ & 0 & 0 & 0 & 0 & 0 & 0 & 0 & 0 & 0 & 0 & 0 & 0 & 0 & 0 & 0 & 1 & 1 \\
\hline TotalF & 7 & 7 & 23 & 146 & 167 & 150 & 98 & 39 & 22 & 6 & 2 & 2 & 0 & 0 & 0 & 0 & 1 & 663 \\
\hline
\end{tabular}

$\mathrm{r}=0.82 . \quad \mathrm{b}_{12}=-2 \cdot 40(\% \mathrm{Hb}$ per sid. per 1,000$)$

$$
\overline{\mathrm{S}} \mathrm{b}_{12}= \pm 8 \cdot 23 \%
$$

The column and line $\mathrm{F}_{1 \mathrm{i}}$ and $\mathrm{F}_{2 \mathrm{j}}$ show the frequency distribution of $\mathrm{Hb}$ in $5 \%$ class intervals and siderocytes in 2 per 1,000 class intervals.

TABLE VI

Correlation table of haemoglobin and siderocyte levels of outgoing recruits

\begin{tabular}{|c|c|c|c|c|c|c|c|c|c|}
\hline \multirow[b]{2}{*}{$\mathrm{Hb} \%$} & \multicolumn{9}{|c|}{ Siderocytes } \\
\hline & 0 & $2-$ & 4- & $6-$ & $8-$ & $10-$ & 12 & 14 & Total $\mathrm{F} 1_{\mathrm{o}}$ \\
\hline $\begin{array}{l}122 \cdot 5- \\
117 \cdot 5- \\
112 \cdot 5- \\
107 \cdot 5- \\
102 \cdot 5- \\
97 \cdot 5- \\
92 \cdot 5- \\
87 \cdot 5- \\
82 \cdot 5- \\
77 \cdot 5- \\
72 \cdot 5- \\
67 \cdot 5- \\
62 \cdot 5- \\
57 \cdot 5- \\
52 \cdot 5- \\
47 \cdot 5- \\
42 \cdot 5-\end{array}$ & $\begin{array}{l}0 \\
2 \\
2 \\
0 \\
0 \\
1 \\
0 \\
0 \\
0 \\
0 \\
0 \\
0 \\
0 \\
0 \\
0 \\
0 \\
0\end{array}$ & $\begin{array}{r}0 \\
0 \\
6 \\
36 \\
23 \\
21 \\
11 \\
0 \\
0 \\
0 \\
0 \\
0 \\
0 \\
0 \\
0 \\
0 \\
0\end{array}$ & $\begin{array}{r}0 \\
0 \\
4 \\
26 \\
69 \\
175 \\
121 \\
12 \\
3 \\
1 \\
0 \\
0 \\
0 \\
0 \\
0 \\
0 \\
0\end{array}$ & $\begin{array}{r}0 \\
0 \\
1 \\
5 \\
0 \\
5 \\
41 \\
21 \\
2 \\
0 \\
1 \\
0 \\
0 \\
0 \\
0 \\
0 \\
0\end{array}$ & $\begin{array}{r}0 \\
1 \\
0 \\
0 \\
1 \\
2 \\
10 \\
17 \\
12 \\
2 \\
1 \\
0 \\
0 \\
0 \\
0 \\
1 \\
0\end{array}$ & $\begin{array}{r}0 \\
0 \\
0 \\
0 \\
0 \\
0 \\
1 \\
6 \\
12 \\
1 \\
0 \\
1 \\
0 \\
0 \\
0 \\
0 \\
0\end{array}$ & $\begin{array}{l}0 \\
0 \\
0 \\
0 \\
0 \\
0 \\
1 \\
0 \\
1 \\
3 \\
0 \\
0 \\
0 \\
0 \\
0 \\
0 \\
0\end{array}$ & $\begin{array}{l}0 \\
0 \\
0 \\
0 \\
0 \\
0 \\
0 \\
1 \\
0 \\
0 \\
0 \\
0 \\
0 \\
0 \\
0 \\
0 \\
0\end{array}$ & $\begin{array}{r}0 \\
3 \\
13 \\
67 \\
93 \\
204 \\
185 \\
57 \\
30 \\
7 \\
2 \\
1 \\
0 \\
0 \\
0 \\
1 \\
0\end{array}$ \\
\hline$\overline{\text { TotalF }} F_{20}$ & 5 & 97 & 411 & 76 & 47 & 21 & 5 & 1 & 663 \\
\hline \multicolumn{10}{|c|}{$\begin{array}{l}\mathrm{r}=0 \cdot 64 . \quad \mathrm{b}_{12}=-1 \cdot 05(\% \mathrm{Hb} \text { per sid. per } 1,000) . \\
\overline{\mathrm{S}}_{12}= \pm 6 \cdot 22 \% \\
\text { The column and line } \mathrm{F}_{1 \mathrm{o}} \text { and } \mathrm{F}_{2 \mathrm{O}} \text { show the frequency distribution of } \mathrm{Hb} \text { in } 5 \% \text { class intervals } \\
\text { and siderocytes in } 2 \text { per } 1,000 \text { class intervals. }\end{array}$} \\
\hline
\end{tabular}


is demonstrated. The third company, however, differs materially from the other two both on incoming and on outgoing.

Tables V and VI are correlation tables of the haemoglobin levels grouped in $5 \%$ class intervals and siderocyte levels in 2 per 1,000 class intervals. From this grouped array the correlation coefficient $(r)$ and the regression coefficient with the haemoglobin as the dependent variable $\left(b_{\mathrm{I}_{2}}\right)$ have been calculated in each case. There is a fairly high degree of correlation $(0.82$ and $0.62 . n=663)$ in each case, but the alteration in the value suggests that other factors than an alteration of haemolytic rate, as shown by the siderocyte levels, have been at work in bringing about the altered picture. This point will be discussed later.

The haemoglobin levels in these tables have been grouped around mid-points falling on the 5 and 0 figures (e.g., 72.5-77.5 mid-point=75), but in order to facilitate a comparison with the figures of the Haemoglobin Survey (M.R.C., 1945) they have also been grouped in $5 \%$ intervals around the 2.5 and $7 \cdot 5$ figures. Fig. 1 shows the frequency histogram of such a grouping for the incoming and outgoing recruits and for the Haemoglobin Survey figures for single males under 20. (The tail ends of the curve have been amalgamated in larger groups.) The precise data for this comparison are shown in Table $\mathrm{X}$.

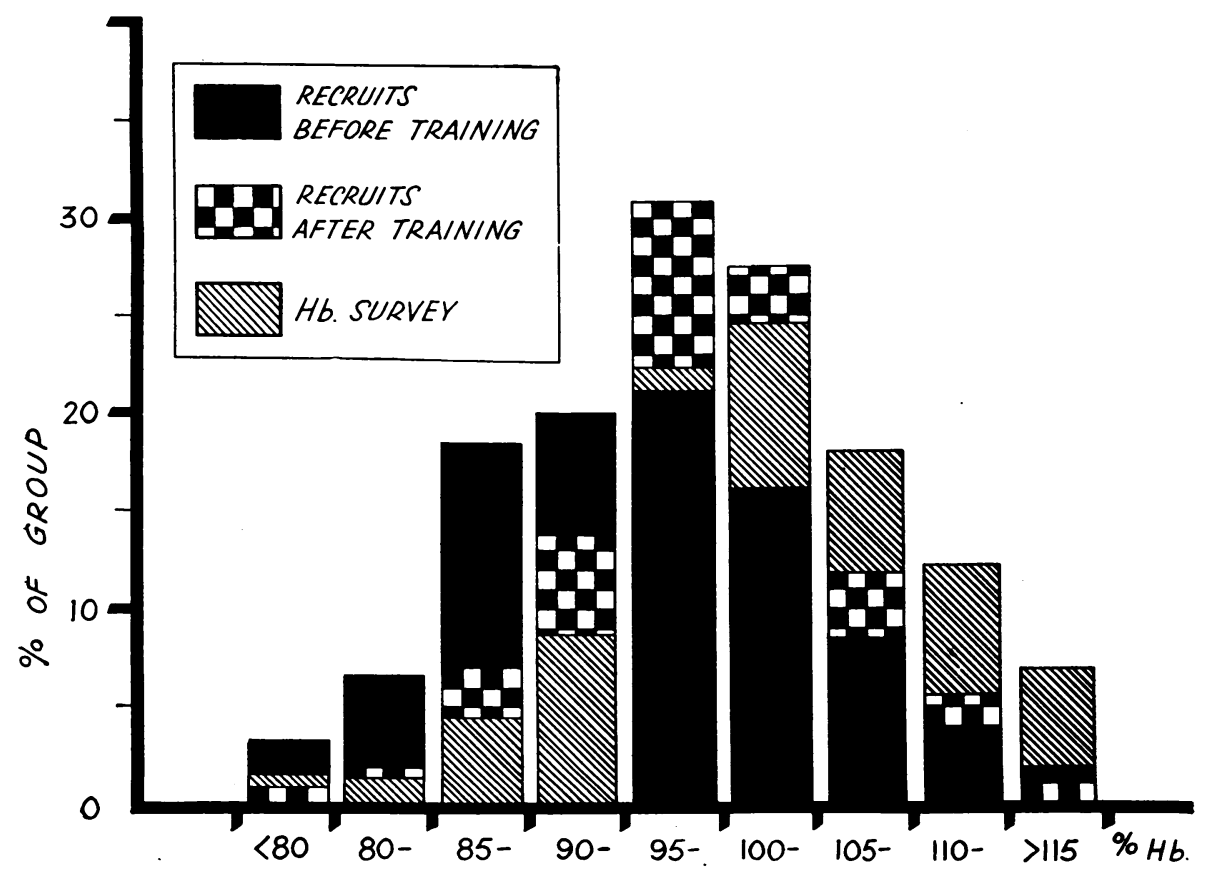

FIG. 1.-Superimposed percentage frequency distributions of haemoglobin levels, in $5 \% \mathrm{Hb}$ class intervals, of recruits before and after training and of 489 males of the same age group. (Hb Survey data.) The actual \% frequency of each group is indicated by the height of the top of the appropriate shading above the base line. 
Table VII is a contingency table of the incoming and outgoing haemoglobin levels, and the extension columns show the behaviour of incoming figures in each class interval. It is shown that there is a marked tendency for incoming values above the value of the class interval of the outgoing mean to fall towards this value, whilst initially low values show a rise.

\section{TABLE VII}

Contingency table of haemoglobin levels of incoming and outgoing recruits

\begin{tabular}{|c|c|c|c|c|c|c|c|c|c|c|c|c|c|c|c|c|c|c|c|c|c|}
\hline $\mathrm{Hb}$ & $\stackrel{\dot{n}}{\dot{\sim}}$ & $\stackrel{n}{\dot{f}}$ & $\stackrel{n}{\tilde{\sim}}$ & $\stackrel{n}{n}$ & $\stackrel{1}{\sim}$ & $\stackrel{1}{\mathfrak{\delta}}$ & $\begin{array}{l}\dot{n} \\
\dot{N}\end{array}$ & $\stackrel{\dot{n}}{\grave{i}}$ & $\stackrel{n}{\stackrel{1}{\dot{d}}}$ & $\stackrel{\substack{1 \\
\dot{\infty}}}{\infty}$ & $\stackrel{n}{\dot{\alpha}}$ & $\begin{array}{l}n \\
\dot{\hat{a}}\end{array}$ & $\begin{array}{r}\stackrel{1}{~} \\
\dot{\delta}\end{array}$ & $\stackrel{n}{\dot{\sigma}}$ & $\stackrel{1}{\stackrel{1}{\Xi}}$ & $\stackrel{1}{\check{\Xi}}$ & $\begin{array}{l}\stackrel{1}{\stackrel{n}{\Xi}} \\
\stackrel{\Xi}{\Xi}\end{array}$ & $\frac{\vec{I}}{\vec{\Xi}}$ & อั & $\underset{\tilde{\sigma}}{\tilde{\omega}}$ & 5 \\
\hline $\begin{array}{l}92 \cdot 5- \\
87 \cdot 5- \\
82 \cdot 5- \\
77 \cdot 5- \\
72 \cdot 5- \\
67 \cdot 5- \\
62 \cdot 5- \\
57 \cdot 5- \\
52 \cdot 5- \\
47 \cdot 5- \\
42 \cdot 5-\end{array}$ & $\begin{array}{l}0 \\
0 \\
0 \\
0 \\
0 \\
0 \\
0 \\
0 \\
0 \\
0 \\
0 \\
0 \\
0 \\
0 \\
0 \\
0 \\
0\end{array}$ & $\begin{array}{l}0 \\
0 \\
0 \\
0 \\
0 \\
0 \\
0 \\
0 \\
0 \\
0 \\
0 \\
0 \\
0 \\
0 \\
0 \\
0 \\
1\end{array}$ & \begin{tabular}{|l|}
0 \\
0 \\
0 \\
0 \\
0 \\
0 \\
0 \\
0 \\
0 \\
0 \\
0 \\
0 \\
0 \\
0 \\
0 \\
0 \\
0 \\
0
\end{tabular} & $\begin{array}{l}0 \\
0 \\
0 \\
0 \\
0 \\
0 \\
0 \\
0 \\
0 \\
0 \\
0 \\
0 \\
0 \\
0 \\
0 \\
0 \\
0 \\
0\end{array}$ & $\begin{array}{l}0 \\
0 \\
0 \\
0 \\
0 \\
0 \\
0 \\
0 \\
0 \\
0 \\
0 \\
0 \\
0 \\
0 \\
0 \\
0 \\
0\end{array}$ & $\begin{array}{l}0 \\
0 \\
0 \\
0 \\
1 \\
0 \\
0 \\
0 \\
0 \\
0 \\
0 \\
0 \\
0 \\
0 \\
0 \\
0 \\
0\end{array}$ & $\begin{array}{l}0 \\
0 \\
0 \\
0 \\
0 \\
0 \\
0 \\
1 \\
0 \\
0 \\
0 \\
0 \\
0 \\
1 \\
0 \\
0 \\
0\end{array}$ & $\begin{array}{l}2 \\
0 \\
1 \\
3 \\
0 \\
1 \\
0 \\
0\end{array}$ & $\begin{array}{l}0 \\
0 \\
1 \\
1 \\
1 \\
4 \\
5 \\
8 \\
7 \\
0 \\
2 \\
1 \\
0 \\
0\end{array}$ & $\begin{array}{r}0 \\
0 \\
0 \\
0 \\
0 \\
10 \\
12 \\
16 \\
14\end{array}$ & $\begin{array}{r}3 \\
9 \\
3 \\
0 \\
1 \\
0 \\
0 \\
0 \\
0\end{array}$ & $\begin{array}{r}0 \\
1 \\
2 \\
14 \\
28 \\
40 \\
43 \\
40 \\
24 \\
7\end{array}$ & $\begin{array}{r}0 \\
1 \\
6 \\
5 \\
11 \\
14 \\
28 \\
15 \\
12 \\
1 \\
0 \\
0 \\
0 \\
0 \\
0 \\
0 \\
0\end{array}$ & $\begin{array}{l}0 \\
1 \\
0 \\
0 \\
0 \\
0 \\
0\end{array}$ & $\begin{array}{l}0 \\
1 \\
1 \\
2 \\
2 \\
3 \\
3 \\
0 \\
1 \\
0 \\
0 \\
0 \\
0 \\
0 \\
0 \\
0 \\
0\end{array}$ & $\begin{array}{l}0 \\
0 \\
0 \\
1 \\
1\end{array}$ & $\begin{array}{l}0 \\
0 \\
0 \\
0 \\
0 \\
0 \\
0 \\
0 \\
0 \\
0 \\
0 \\
0 \\
0 \\
0 \\
0 \\
0 \\
0\end{array}$ & $\begin{array}{r}1 \\
4 \\
11 \\
11 \\
39 \\
69 \\
118 \\
154 \\
131 \\
95 \\
23 \\
10 \\
3 \\
1 \\
1 \\
2 \\
0 \\
1\end{array}$ & $\begin{array}{r}1 \\
4 \\
10 \\
27 \\
44 \\
45 \\
17 \\
9 \\
1 \\
0 \\
0 \\
0 \\
0 \\
0 \\
0 \\
0 \\
0\end{array}$ & $\begin{array}{r}1 \\
9 \\
11 \\
40 \\
46 \\
16 \\
7 \\
3 \\
0 \\
0 \\
0\end{array}$ & $\begin{array}{r}14 \\
33 \\
89 \\
106 \\
87 \\
80 \\
20 \\
10\end{array}$ \\
\hline $\begin{array}{l}\text { otal } \\
\text { F } 1_{0}\end{array}$ & 0 & 1 & 0 & 0 & 0 & 1 & 2 & 7 & 30 & 57 & 185 & 204 & 93 & 67 & 13 & 3 & 0 & 663 & - & - & - \\
\hline
\end{tabular}

The column and line $F 1_{1}$ and $F 1_{0}$ show the frequency distribution of $\mathrm{Hb}$ in $5 \%$ class intervals.

The column "Down" shows a fall from the original class interval; "Stat." remains within the original class interval; and "Up" shows a rise from the original class interval.

This point is more clearly demonstrated by Fig. 2, which shows the percentage in each incoming class interval that rise, fall, or remain within their original class interval.

Table VIII shows a comparison between the outgoing and " normal" siderocyte figures. The " normals" derived from the data of Case, Ladan, and Nutt (1945) are of 68 males aged 15-25. After training, the siderocyte levels do not differ significantly from the values for these " normals." 


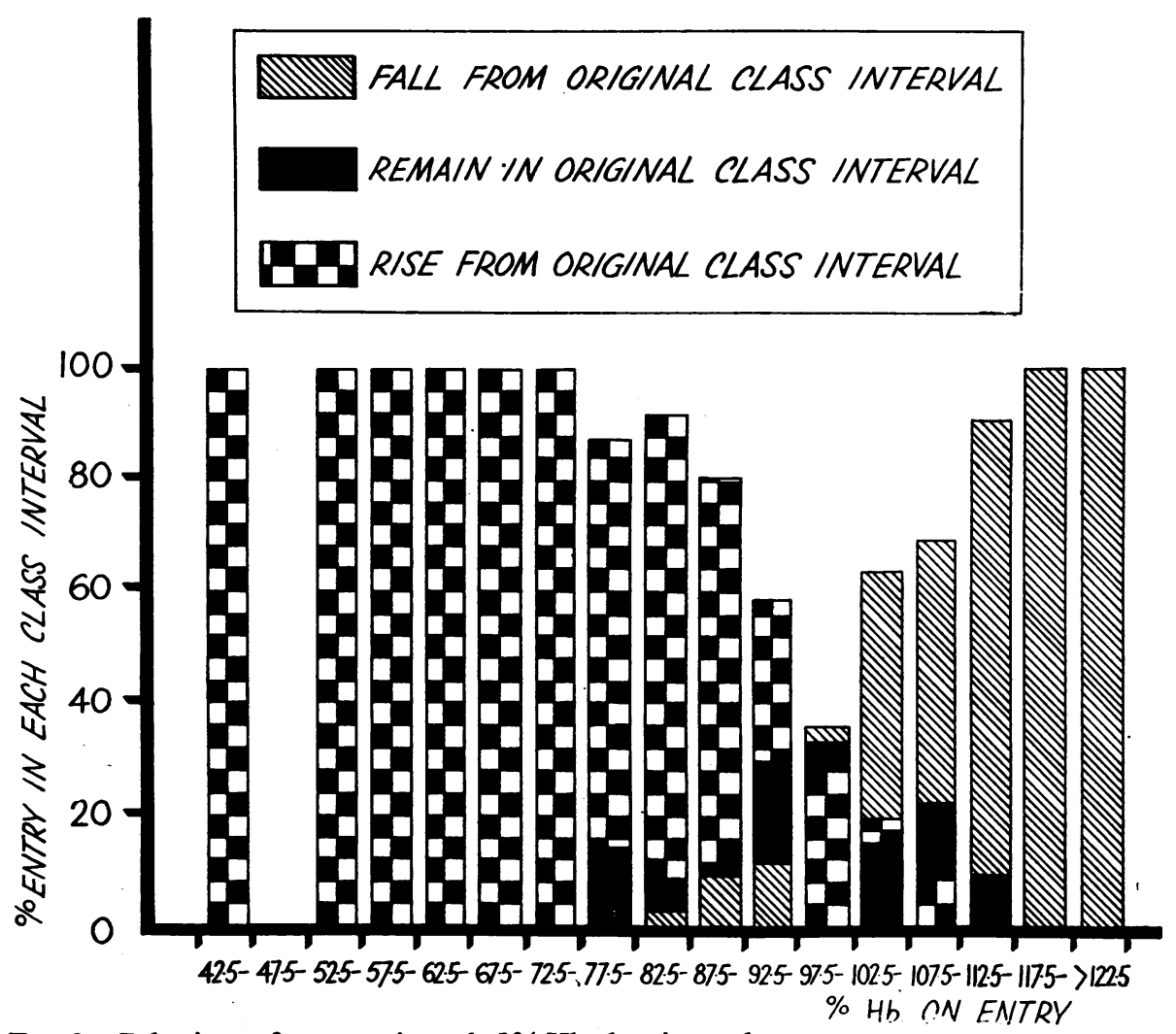

Fig. 2.-Behaviour of entrants in each $5 \% \mathrm{Hb}$ class interval.

TABLE VIII

Comparison of siderocyte levels of 663 recruits, after training, with levels of 68 " normal" males age 15-25. (Data of Case, Ladan, and Nutt, 1945)

\begin{tabular}{|c|c|c|c|c|c|}
\hline & & $\mathbf{n}$ & $\begin{array}{l}\text { mean } \\
\text { (Sids. per } \\
1,000)\end{array}$ & $\sigma$ & $\mathbf{V}$ \\
\hline$\underset{\text { "Necruits }}{\text { Normals ," }}$ & $\begin{array}{l}\cdots \\
\cdots\end{array}$ & $\begin{array}{r}663 \\
68\end{array}$ & $\begin{array}{l}4 \cdot 7 \\
5 \cdot 0\end{array}$ & $\begin{array}{l}2 \cdot 0 \\
2 \cdot 3\end{array}$ & $\begin{array}{l}41 \cdot 8 \% \\
45 \cdot 0 \%\end{array}$ \\
\hline Difference $\ldots$ & .. & & $0 \cdot 3$ & & $4 \cdot 2 \%$ \\
\hline $\begin{array}{r}\text { Significance of } \\
\text { Difference }\end{array}$ & . & & $t=1 \cdot 17 \quad P=\cdot 24$ & & $t=1.05 \quad P=\cdot 27$ \\
\hline
\end{tabular}

Fig. 3 shows the frequency histograms of the incoming, 'outgoing, and " normal " values in 2 per 1,000 class intervals. 


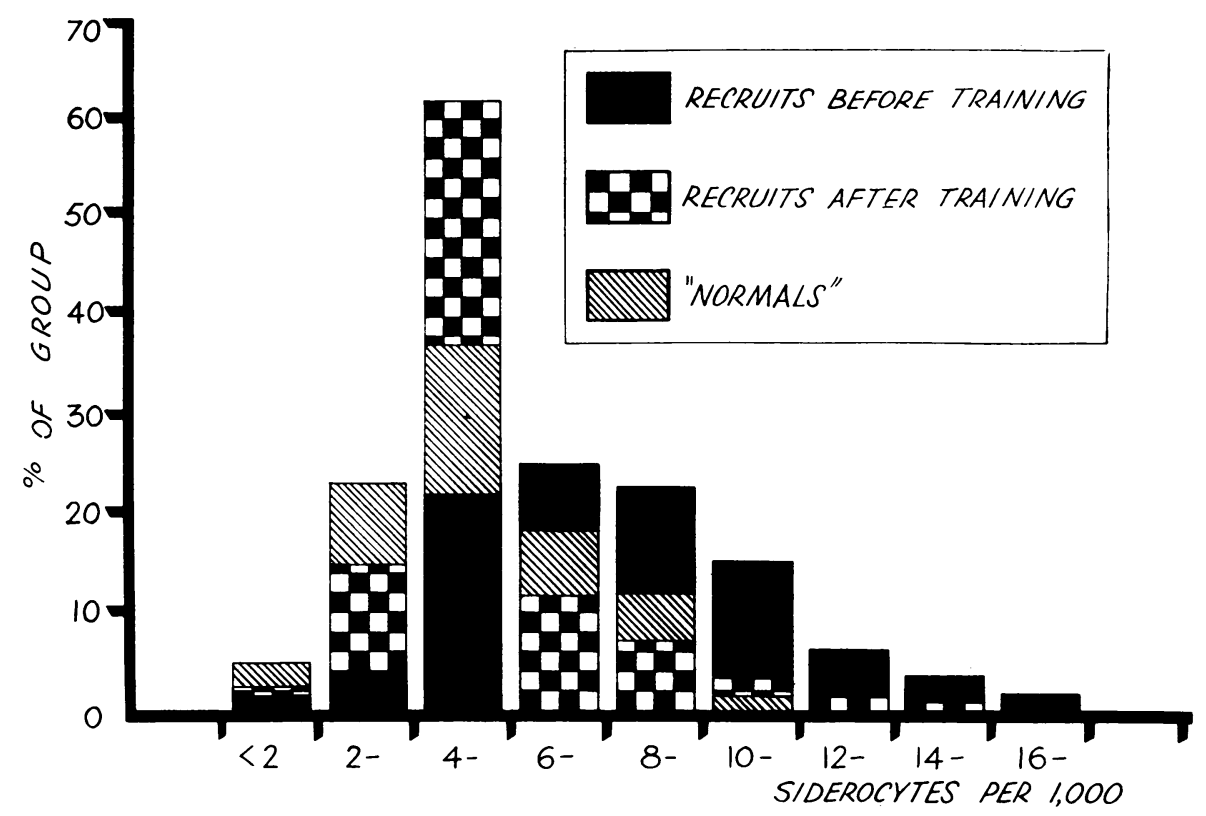

FIG. 3.- Superimposed percentage frequency distributions of siderocyte levels, in 2 per 1,000 class intervals, of recruits before and after training, and of 68 normal males of the same age group. Conventions of superposition as in Fig. 1.

Tables IX and $\mathrm{X}$ show the figures for the haemoglobin levels before and after training, and figures derived from the data of Davidson et al. (1943) and the Haemoglobin Survey (M.R.C., 1945). For sampling reasons discussed at length in the Survey, and mentioned here previously, no attempt has been made to calculate significance of differences for this data.

\section{TABLE IX}

Comparison of haemoglobin levels of 663 recruits, before and after training, with haemoglobin levels of random samples of schoolboys, students, and factory workers (male) (data of Davidson, Donaldson, Lindsay, and McSorley, 1943) and 489 single males below the age of 20 (Haemoglobin Survey Committee, M.R.C., 1945)

\begin{tabular}{|c|c|c|c|c|c|c|}
\hline Group & & & $\mathrm{n}$ & Mean & $\sigma$ & V \\
\hline $\begin{array}{l}\text { Recruits before training } \\
\text { Recruits after training }\end{array}$. $\begin{array}{l}\text { Schoolboys, 13-18 } \\
\text { Male students } \ldots \\
\text { Male factory workers } \\
\text { Single males below } 20\end{array}$ & $\begin{array}{l}\cdots \\
\cdots \\
\cdots \\
\cdots \\
\cdots\end{array}$ & $\begin{array}{l}\cdots \\
\cdots \\
\cdots \\
\cdots \\
\cdots\end{array}$ & $\begin{array}{l}663 \\
663 \\
159 \\
100 \\
123 \\
489\end{array}$ & $\begin{array}{r}94 \cdot 5 \\
98 \cdot 7 \\
99 \cdot 5 \\
105 \cdot 5 \\
100 \cdot 5 \\
101 \cdot 7\end{array}$ & $\begin{array}{l}9 \cdot 49 \\
7 \cdot 31 \\
5 \cdot 8 \\
5 \cdot 1 \\
6 \cdot 5 \\
9 \cdot 2\end{array}$ & $\begin{array}{l}10 \cdot 0 \% \\
7.4 \% \\
5 \cdot 8 \% \\
5 \cdot 8 \% \\
6.5 \% \\
9.0 \%\end{array}$ \\
\hline
\end{tabular}

The parameters, apart from the means, of Davidson's data were computed from published data grouped in $10 \%$ class intervals. 


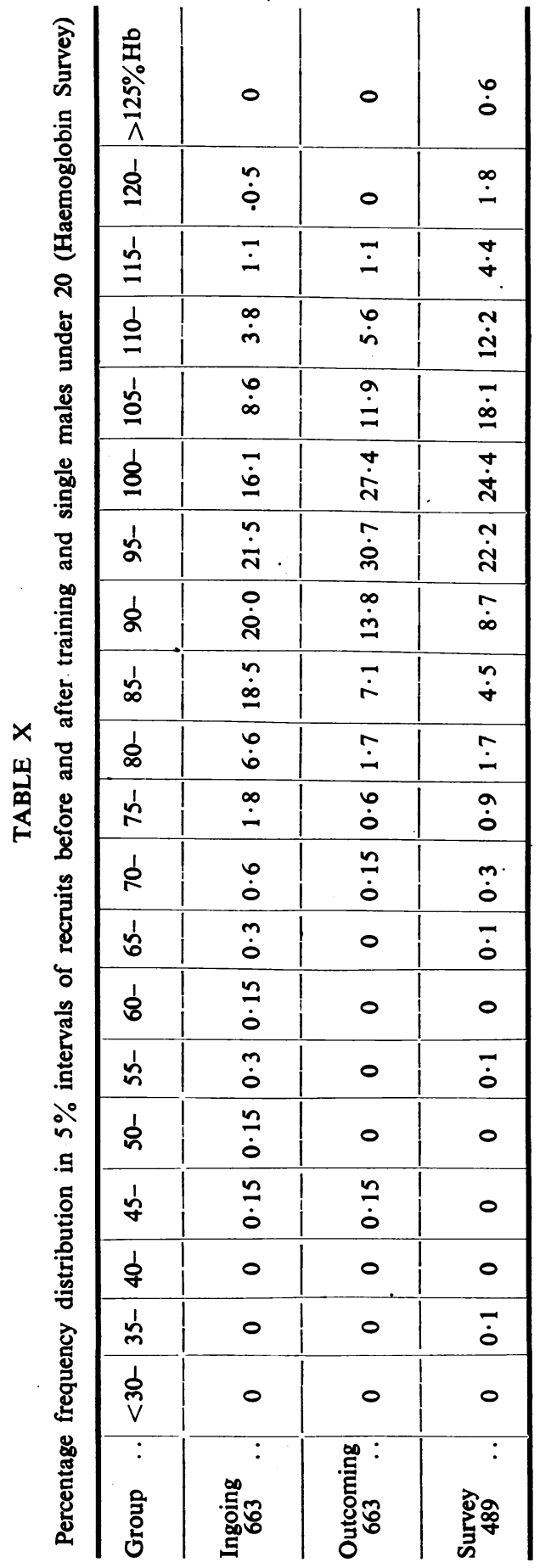


TABLE XI

The effects of ferrous sulphate therapy on " anaemic " incoming recruits

\begin{tabular}{|c|c|c|c|c|c|c|c|c|c|c|c|c|c|}
\hline \multirow[b]{2}{*}{ Group } & \multirow[b]{2}{*}{$n$} & \multicolumn{6}{|c|}{ Incoming } & \multicolumn{6}{|c|}{ Outgoing } \\
\hline & & Hb.m. & $\sigma$ & $\mathbf{v}$ & S.m. & $\sigma$ & $\mathrm{V}$ & Hb.m. & $\sigma$ & $\mathbf{v}$ & S.m. & $\sigma$ & $\mathbf{v}$ \\
\hline $\begin{array}{l}\text { Treated } \\
\text { Untreated }\end{array}$ & $\begin{array}{l}51 \\
42\end{array}$ & $\begin{array}{l}78 \cdot 4 \\
82 \cdot 8\end{array}$ & $\begin{array}{l}7 \cdot 2 \\
3 \cdot 8\end{array}$ & $\begin{array}{l}9 \cdot 2 \% \\
4.6 \%\end{array}$ & $\begin{array}{r}9.9 \\
11.0\end{array}$ & $\begin{array}{l}4 \cdot 0 \\
4 \cdot 4\end{array}$ & $41 \%$ & $\begin{array}{l}94 \cdot 6 \\
95 \cdot 0\end{array}$ & $\begin{array}{l}6 \cdot 3 \\
9 \cdot 9\end{array}$ & $\begin{array}{r}6.7 \% \\
10.4 \%\end{array}$ & $\begin{array}{l}5 \cdot 0 \\
4 \cdot 9\end{array}$ & \begin{tabular}{|l|}
$1 \cdot 9$ \\
$2 \cdot 2$
\end{tabular} & $38 \%$ \\
\hline \multirow{3}{*}{\multicolumn{2}{|c|}{ Difference of out }} & tgoing & values & $\quad \ldots$ & $\ldots$ & . & & 0.4 & & $3 \cdot 7 \%$ & 0.1 & & $7 \%$ \\
\hline & & & & & & & $\mathbf{t}$ & 0.63 & & 2.97 & 0.46 & & $1 \cdot 12$ \\
\hline & & & & & & & $\mathbf{P}$ & 0.5 & & 0.003 & 0.58 & & 0.25 \\
\hline
\end{tabular}

\section{Discussion}

For convenience it is proposed to discuss the foregoing results here, and to deal with the details of the recruits classified as " anaemics " in a separate section.

\section{Haemoglobin Levels}

The mean haemoglobin level of these recruits on entering the training centre was definitely lower than accepted standards for males of this age group (17-20). However, mean haemoglobin values seem to be associated with occupation rather than age group, and Table IX shows several groups for comparison. The recruits, on entering, were obviously drawn from a variety of occupations. During training the mean value rose considerably, and the final figure of $98.7 \%$ can probably be considered as a fairly satisfactory value. Not only does the mean value rise, however, but the scatter around the mean (coefficient of variation) is also significantly changed, becoming considerably smaller. This is brought about to a large extent by the rise of the lower values; but a second factor-the fall of initially high values-also comes into play in bringing about this contraction. This fall of the higher values is well shown by Table VII and Fig. 2, and is of interest because it gives rise to the hypothesis that under training there is a tendency to converge upon a mean value, which is perhaps physiologically more suited to the particular mode of life for which the training is a preparatory process. If further studies on similar lines should substantiate this hypothesis, then an explanation is forthcoming for the occupational fluctuation of mean values observed in the Haemoglobin Survey. It would imply that for a given mode of existence there is an optimum level of respiratory pigment, which is not necessarily the maximum observed in so-called " normal " groups. 
There are several possible explanations for the mechanism whereby the reduction of the higher values is brought about, which may be summarized as follows:-

(1) Hydration balance may be a factor, the haemoglobin concentration being affected by fluid shift rather than by alteration of the total amount of circulating pigment.

(2) Faulty ventilation, due either to bad breathing habits or to variations of alveolar epithelial permeability, may have produced a compensatory rise, which is corrected by improved oxygenation after training.

(3) A true dynamic haematological imbalance may have existed, which is corrected by a haemolytic process overtaking the haemopoietic process until an optimum level is reached. This process could be brought about by retardation of haematopoiesis with no change in haemolytic rate, by acceleration of destruction of erythrocytes with no increase of haematopoiesis, or by both mechanisms at work simultaneously.

(4) More than one of these processes may be at work at the same time, since the explanations are not necessarily mutually exclusive.

A comparison of the observed values for the recruits before and after training with data on large groups of males collected by other workers show that under training, the haemoglobin values approximate fairly closely to those of males of the same age group, with the reservations inherent in the occupational fluctuation, and also reveals that before training a disproportionately large percentage of the recruits had low haemoglobin values (Tables IX, X, and XII), but that after training this figure is much the same as in the males under 20 examined in the Haemoglobin Survey.

\section{Siderocytes}

The siderocyte is an ageing erythrocyte, and appears to be a good index of the percentage of erythrocytes being removed from the circulation at any given time (Case, 1943, 1945b). A study of these cells should therefore provide some information about the dynamics of the erythron in such groups of subjects as we are now dealing with. Normal levels have been established (Case et al., 1945) and the raw data are available for comparison purposes.

In the incoming recruits, the siderocyte mean is shown to be raised, but after training the picture is not significantly different from that presented by the normals previously studied. The mean and coefficient of variation approximate very closely, and the distribution graphs are very similar.

The correlation coefficients of the siderocytes and haemoglobin levels are of interest. On incoming, the coefficient is high, suggesting that much of the variance of $\mathrm{Hb}$ levels is explained by haemolytic processes, but after training, when the siderocyte picture is normal, the correlation has dropped, which suggests that other mechanisms are at work-a possibility adumbrated above.

The coefficients of regression calculated from the grouped data are of value, since, with their corrected standard errors of estimate $\left(\overline{\mathrm{S}}_{12}\right)$, they allow of a forecast 
of the amount of change of $\mathrm{Hb}$ level expected per unit siderocyte change if the factors involved remain constant. A study of the observed changes and calculated changes will help in elucidating the number of mechanisms at work. This technique will be used in the section dealing with the "anaemics."

The significance attached to the difference of the various parameters of the siderocyte figures for the incoming and outgoing recruits is greater than that attached to the difference of the haemoglobin parameters, and this suggests that the siderocyte might be an even more sensitive indicator of the effects of training than the haemoglobin levels themselves, though obviously it is still better to use both indices.

\section{Homogeneity of Material}

The entrants were divided into three sections. As has been previously mentioned, the first two sections were selected by the same methods, and had had about 14 days' previous training before entering the P.D.C. The third section was selected by a different type of selection board, and arrived without any preliminary training whatsoever.

The haemoglobin and siderocyte figures for the third section differ very materially from those of the other two sections, which, statistically, may be regarded as being drawn from the same haematological universe. The third company came in with a much higher haemoglobin mean, which actually fell under training, but with a lower siderocyte mean, which fell under training to the same value as the other sections. Furthermore, some members of the third company actually became " anaemic" during the training period (see below).

There was no reason to suppose that the third company differed from the remaining companies in social and occupational background, so it would seem probable that the differences found must be attributable to differences in the mechanism of selection or to the alteration in time relationship of the training period to the observations (or to both these factors).

There is, of course, no evidence in these data concerning the first of these alternatives, but there are indications that the second concept may play a quite considerable part in the observed phenomena. The third company, with a lower haemolytic tendency as shown by the siderocyte levels, came in with a higher haemoglobin mean, including a fairly large number of high values which decreased, and a number who actually became " anaemic " during training. If the hypothesis of the convergence upon an optimum mean related to the environmental conditions is sound, it may well be that such mechanisms as are brought into play do not at once establish the desired equilibrium state, but tend to overact at first, causing an oscillation around the optimum, possibly of progressively decreasing magnitude. This hypothetical optimum does not interfere with the concept of diurnal variation, being itself subject to such change. It is possible that the extra 14 days' training (25\% of the total time) was a sufficient length of time to allow the adjusting forces to come into play and produce the discrepancies in the incoming observations, 
and that the magnitude of the oscillation had decreased sufficiently in the final 14 days to allow the observed difference to occur.

\section{Studies on " Anaemics"}

As previously stated, for the purpose of this research, all recruits who on entry returned a haemoglobin value of less than $86 \%$ were arbitrarily classified as " anaemics," and were made the subject of more extensive studies. These studies are, in fact, a detailed investigation of the low-value tail of the distribution curve of the haemoglobin levels.

In addition to the investigations discussed under " Methods," these " anaemics" were divided into two approximately equal groups, and 9 grains of ferrous sulphate administered daily for a period of 30 to 50 days to one group. The division into groups was intended to be random, but there is some reason to believe that there was a slight bias in favour of treating the worst anaemics (i.e., those with the lowest levels) with iron, this bias being connected with " ethical" considerations.

Results.-Table XI shows the effect of iron therapy upon the anaemic group receiving ferrous sulphate contrasted with the behaviour of the control group of anaemics who were not so treated. Apart from a smaller coefficient of variation in the outgoing levels of the iron-treated recruits, there is no evidence that the exhibition of iron influenced the behaviour of the haemoglobin values, and, since both groups improved markedly under training, this means that there is here no evidence of an iron-deficiency anaemia requiring iron supplementary to the amount provided in the diet. The figures do not, of course, show that iron deficiency played no part in the aetiology of the anaemia, since the diet contained reasonable amounts of iron, but, since the improvement took place so quickly without supplementing the diet, any such deficiency must have been of a minor degree.

\section{TABLE XII}

Incidence of anaemia in recruits before and after training, and in males under 20 in Haemoglobin Survey

\begin{tabular}{ccccc}
\hline & Before Training & After Training & Hb Survey \\
\hline$<86 \% \mathrm{Hb} \ldots$ & $\ldots$ & $\begin{array}{l}93(14 \cdot 0 \%) \\
11(1.7 \%)\end{array}$ & $\begin{array}{r}25(3 \cdot 8 \%)(8 \text { residual }) \\
2(0.3 \%)(1 \text { residual })\end{array}$ & $\begin{array}{l}3 \cdot 8 \% \\
0.6 \%\end{array}$ \\
\hline
\end{tabular}

Table XII shows the incidence of " anaemia" in the recruits before and after training compared with the incidence of " anaemia " in the Haemoglobin Survey's series. Before training there was a marked preponderance of low levels, but after training the incidence was much the same as in the Survey's group.

Of the 93 anaemics of the incoming group, only 8 were " anaemic" at the end of the training period, and of the remaining 570 recruits who were not " anaemic " on entry, 17 became anaemic during the course; 14 of these 17 were from the third section. 
Table XIII shows the details of the 17 entrants who became " anaemic" and also shows the behaviour of the haemoglobin levels calculated from the regression coefficients of the whole group, and the residual deviations $\left(\mathrm{z}^{1}\right)$ from the expected behaviour. This analysis shows that 4 out of 17 cases lie outside one standard deviation of the residuals and 1 outside two standard deviations on the calculations based on the incoming data. This is much what would be expected if the association of siderocytes and haemoglobin contributed the same amount to the erythron dynamics in each case. From the second calculation, based on the outgoing data, the observed differences of haemoglobin exceed the calculated differences by more than one standard deviation in 10 out of 17 cases, by more than two standard deviations in 5 cases, and three standard deviations in 1 case. This is much more than is expected if the interplay of causes is similar in the "anaemics " and the recruits after training.

It therefore appears that these entrants who became " anaemic " during training show a similar haemoglobin-siderocyte pattern to the whole body of recruits

TABLE XIII

Details of 17 recruits who became " anaemic" during training

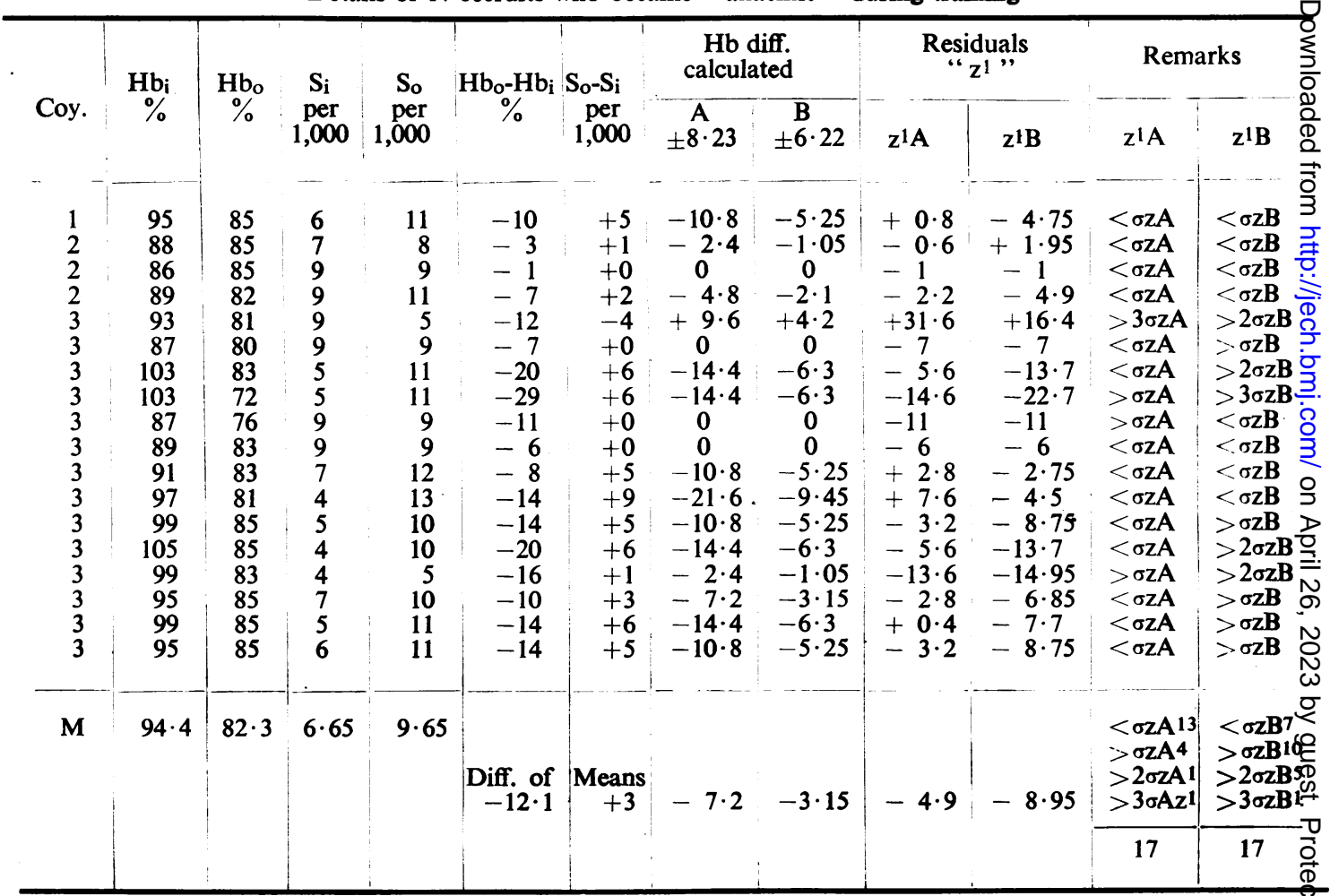

Calculated $\mathrm{Hb}$ differences $\mathrm{A}$ and $\mathrm{B}$ are computed from the regression coefficients $\mathrm{b}_{12}=2 \cdot 40$. $\overline{\mathrm{S}} \mathrm{b}_{12}= \pm 8 \cdot 23 \%$ and $b_{12}=-1 \cdot 05 . \quad \bar{S} b_{12}= \pm 6 \cdot 22 \% . \quad \sigma z=\bar{S} b_{12}$. 
before training, but little similarity to the after-training picture. Since the great majority of these groups are drawn from the third section, this finding lends some support to the time-relation theory already outlined.

Table XIV shows the details and a similar analysis of the 8 recruits who remained " anaemic" throughout the course. Here the observed differences agree equally well with differences computed from each regression coefficient, in each case 2 out of 8 lying outside one standard deviation and 1 outside two standard deviations. In fact, the observed differences tend to lie between the two sets of calculated differences, suggesting that the training has brought about only a part of the change observed in the bulk of the entrants.

TABLE XIV

Details of 8 recruits, initially " anaemic," who remained so

\begin{tabular}{|c|c|c|c|c|c|c|c|c|c|c|c|c|}
\hline & \multirow{2}{*}{$\begin{array}{l}\mathrm{Hb}_{\mathrm{i}} \\
\%\end{array}$} & \multirow{2}{*}{$\underset{\%}{H_{0} b_{0}}$} & \multirow{2}{*}{$\begin{array}{c}S_{i} \\
\text { per } \\
1,000\end{array}$} & \multirow{2}{*}{$\begin{array}{c}\text { So } \\
\text { per } \\
1,000\end{array}$} & \multirow{2}{*}{$\underset{\%}{\mathbf{H b} \mathbf{b}_{\mathbf{o}}-\mathbf{H} \mathbf{b}_{\mathbf{i}}}$} & \multirow{2}{*}{$\begin{array}{c}\mathbf{S}_{\mathbf{o}}-\mathbf{S}_{\mathbf{i}} \\
\text { per } \\
1,000\end{array}$} & \multicolumn{2}{|c|}{$\begin{array}{l}\text { Hb diff. } \\
\text { calculated }\end{array}$} & \multicolumn{2}{|c|}{$\begin{array}{l}\text { Residuals } \\
\mathrm{z}^{1} "\end{array}$} & \multicolumn{2}{|c|}{ Remarks } \\
\hline & & & & & & & $\begin{array}{c}\mathrm{A} \\
\pm 8 \cdot 23\end{array}$ & $\begin{array}{c}\text { B } \\
\pm 6 \cdot 22\end{array}$ & $\mathbf{z}^{1} \mathbf{A}$ & $\mathbf{z}^{1 B}$ & $\mathbf{z}^{1} \mathbf{A}$ & $\mathbf{z}^{1} \mathbf{B}$ \\
\hline & $\begin{array}{l}79 \\
58 \\
69 \\
82 \\
81 \\
77 \\
46 \\
85\end{array}$ & $\begin{array}{l}79 \\
76 \\
78 \\
81 \\
82 \\
83 \\
48 \\
85\end{array}$ & $\begin{array}{r}6 \\
10 \\
13 \\
10 \\
14 \\
13 \\
30 \\
11\end{array}$ & $\begin{array}{r}8 \\
6 \\
8 \\
10 \\
12 \\
8 \\
8 \\
11\end{array}$ & $\begin{array}{r}0 \\
+18 \\
+9 \\
+1 \\
+1 \\
+6 \\
+2 \\
0\end{array}$ & $\begin{array}{c}+2 \\
-4 \\
-5 \\
0 \\
-2 \\
-5 \\
-22 \\
0\end{array}$ & $\begin{array}{c}-4.8 \\
+9.6 \\
+12.0 \\
0 \\
-4.8 \\
+12.0 \\
+28.8 \\
0\end{array}$ & $\begin{aligned} & 2 \cdot 1 \\
+ & 4 \cdot 2 \\
+ & 5 \cdot 25 \\
& 0 \\
- & 2 \cdot 1 \\
+ & 5 \cdot 25 \\
+ & 12 \cdot 6 \\
& 0\end{aligned}$ & $\begin{array}{l}+4 \cdot 8 \\
+8 \cdot 4 \\
+3 \\
+1 \\
+3 \cdot 8 \\
+6 \cdot 0 \\
+26 \cdot 8 \\
0\end{array}$ & $\begin{array}{c}+2 \cdot 1 \\
-13 \cdot 8 \\
-3 \cdot 75 \\
-1 \\
+1 \cdot 1 \\
-0.75 \\
+10.6 \\
0\end{array}$ & $\begin{array}{c}<\sigma \mathrm{ZAA} \\
>\sigma \mathrm{zA} \\
<\sigma \mathrm{zA} \\
<\sigma \mathrm{zA} \\
<\sigma \mathrm{zA} \\
<\sigma \mathrm{zA} \\
>3 \sigma \mathrm{zA} \\
=\end{array}$ & $\begin{array}{c}<\sigma z \mathrm{zB} \\
>2 \sigma z \mathrm{zB} \\
<\sigma z \mathrm{zB} \\
<\sigma z \mathrm{zB} \\
<\sigma z \mathrm{zB} \\
<\sigma z \mathrm{zB} \\
>\sigma \mathrm{zB} \\
=\end{array}$ \\
\hline \multirow[t]{2}{*}{$\mathbf{M}$} & \multirow[t]{2}{*}{$72 \cdot 1$} & \multirow[t]{2}{*}{$76 \cdot 5$} & \multirow[t]{2}{*}{$13 \cdot 4$} & \multirow[t]{2}{*}{$8 \cdot 9$} & \multirow[t]{2}{*}{$\begin{array}{c}\text { Diff. of } \\
\text { Means } \\
+4 \cdot 4\end{array}$} & \multirow[t]{2}{*}{$-4 \cdot 5$} & \multirow[t]{2}{*}{$+10 \cdot 8$} & \multirow[t]{2}{*}{$+4 \cdot 7$} & \multirow[t]{2}{*}{$+6 \cdot 4$} & \multirow[t]{2}{*}{+0.3} & $\begin{array}{l}<\sigma \mathrm{ZA}^{6} \\
>\sigma \mathrm{ZA}^{2} \\
>2 \sigma \mathrm{ZA}^{1} \\
>3 \sigma \mathrm{ZA}^{1}\end{array}$ & $\begin{array}{l}<\sigma \mathrm{zB} 6 \\
>\sigma \mathrm{zB} 2 \\
>2 \sigma \mathrm{zB} 1 \\
>3 \sigma \mathrm{zB} 0\end{array}$ \\
\hline & & & & & & & & & & & 8 & 8 \\
\hline
\end{tabular}

Table XV shows the cytological analysis of the 93 " anaemics," subdivided into those receiving iron therapy and those not receiving it.

Both on entry and outgoing, the " anaemics" fell quite naturally into three classifications-normochromic normocytic anaemias, hypochromic normocytic anaemias, and hypochromic microcytic anaemias. These diagnoses were made on microscopical criteria, it not being practicable to make haematocrit or cell diameter studies. The table shows the cytological improvement resulting from training, and again reveals that iron therapy does not appear to have influenced the end result. 
TABLE XV

Cytological analysis of 93 "Anaemics"

\begin{tabular}{|c|c|c|c|c|c|c|c|c|c|c|c|c|c|c|c|c|c|}
\hline \multicolumn{9}{|c|}{ Incoming } & \multicolumn{9}{|c|}{ Outgoing } \\
\hline \multicolumn{5}{|c|}{$+\mathrm{FeSO}_{4}$ Therapy } & \multicolumn{4}{|c|}{-FéSO 4 Therapy } & \multicolumn{5}{|c|}{$+\mathrm{FeSO}_{4}$ Therapy } & \multicolumn{4}{|c|}{$-\mathrm{FeSO}_{4}$ Therapy } \\
\hline & $\mathbf{n}$ & A & $\mathbf{P}$ & $\mathbf{A}+\mathbf{P}$ & $n$ & A & $\mathbf{P}$ & $A+P$ & & $\mathrm{n}$ & A & $\mathbf{P}$ & $\mathbf{A}+\mathbf{P}$ & $\mathrm{n}$ & A & $\mathbf{P}$ & $\mathbf{A}+\mathbf{P}$ \\
\hline N.N. & 24 & 0 & 0 & 0 & 21 & 1 & 0 & 0 & $\begin{array}{l}\text { N.N. } \\
\text { H.N. } \\
\text { H.M. }\end{array}$ & $\begin{array}{r}24 \\
0 \\
0\end{array}$ & $\begin{array}{l}0 \\
0 \\
0\end{array}$ & $\begin{array}{l}0 \\
0 \\
0\end{array}$ & $\begin{array}{l}0 \\
0 \\
0\end{array}$ & $\begin{array}{r}21 \\
0 \\
0\end{array}$ & $\begin{array}{l}0 \\
0 \\
0\end{array}$ & $\begin{array}{l}0 \\
0 \\
0\end{array}$ & $\begin{array}{l}0 \\
0 \\
0\end{array}$ \\
\hline H.N. & 20 & 3 & 2 & 1 & 7 & 1 & 1 & 1 & $\begin{array}{l}\text { N.N. } \\
\text { H.N. } \\
\text { H.M. }\end{array}$ & $\begin{array}{r}14 \\
6 \\
0\end{array}$ & $\begin{array}{l}0 \\
0 \\
0\end{array}$ & $\begin{array}{l}0 \\
0 \\
0\end{array}$ & $\begin{array}{l}0 \\
0 \\
0\end{array}$ & $\begin{array}{l}4 \\
3 \\
0\end{array}$ & $\begin{array}{l}0 \\
1 \\
0\end{array}$ & $\begin{array}{l}0 \\
1 \\
0\end{array}$ & $\begin{array}{l}0 \\
1 \\
0\end{array}$ \\
\hline H.M. & 7 & 5 & 2 & 2 & 14 & 5 & 1 & 1 & $\begin{array}{l}\text { N.N. } \\
\text { H.N. } \\
\text { H.M. }\end{array}$ & $\begin{array}{l}4 \\
0 \\
3\end{array}$ & $\begin{array}{l}\mathbf{0} \\
\mathbf{0} \\
2\end{array}$ & $\begin{array}{l}0 \\
0 \\
1\end{array}$ & $\begin{array}{l}0 \\
0 \\
1\end{array}$ & $\begin{array}{r}12 \\
0 \\
2\end{array}$ & $\begin{array}{l}0 \\
0 \\
1\end{array}$ & $\begin{array}{l}0 \\
0 \\
1\end{array}$ & $\begin{array}{l}0 \\
0 \\
1\end{array}$ \\
\hline \multirow[t]{2}{*}{ Total . } & 51 & 8 & 4 & 3 & 42 & 7 & 2 & 2 & & 51 & 2 & 1 & 1 & 42 & 2 & 2 & 2 \\
\hline & & & & & & In & & $\mathrm{O}$ & ut & & & & In & & & $\mathrm{Ou}$ & \\
\hline \multirow{2}{*}{\multicolumn{2}{|c|}{$\begin{array}{c}\text { Total: both } \\
\text { groups }\end{array}$}} & & $\begin{array}{l}\mathrm{N} \\
\mathrm{M}\end{array}$ & $\begin{array}{l}\ldots \\
\cdots \\
\cdots\end{array}$ & $\begin{array}{l}4 \\
2 \\
2\end{array}$ & $\begin{array}{l}15 \\
27 \\
1\end{array}$ & & $\begin{array}{r}79 \\
9 \\
5\end{array}$ & & $\begin{array}{l}\mathbf{A} \\
\mathbf{P} \\
\mathbf{A}+\end{array}$ & & $\begin{array}{l}\ldots \\
. \\
\ldots\end{array}$ & $\begin{array}{r}15 \\
5 \\
4\end{array}$ & & & $\begin{array}{l}4 \\
3 \\
3\end{array}$ & \\
\hline & & $\mathrm{n}$ & & . & 9 & & & 93 & & & & & & & & & \\
\hline
\end{tabular}

N.N. = Normochromic normocytic. H.N. =Hypochromic normocytic. H.M. =Hypochromic microcytic.

$\mathbf{A}=$ Anisocytosis. $\mathbf{P}=$ Poikilocytosis. $\mathbf{A}+\mathbf{P}=$ Both present. (A subject showing $\mathbf{A}+\mathbf{P}$ would be entered under $\mathbf{A}, \mathbf{P}$ and $\mathbf{A}+\mathbf{P}$.)

All the outgoing subjects showing $\mathbf{A}, \mathbf{P}$ or $\mathbf{A}+\mathbf{P}$ were residual from their original group.

Table XVI shows the detailed cytological analysis of the 11 " anaemics" who entered with a haemoglobin below $76 \%$. Of these, one was probably a case of " splenic anaemia" and one gave a history of recent exposure to lead hazard. In one, the white cell picture was abnormal, and this was the only abnormality in differential counts noticed in the whole anaemia investigation.

Discussion of the "Anaemic" Recruits

A rather unexpectedly high proportion of the recruits were found to have haemoglobin levels below $86 \%$ on admission ( 93 out of $663=14 \%$ ), and a much smaller fraction (11 out of $663=1.7 \%$ ) fell below $76 \%$. After the course, the 
TABLE XVI

Cytological analysis of 11 " anaemics " below $76 \% \mathrm{Hb}$

\begin{tabular}{|c|c|c|c|c|c|c|c|c|c|c|c|c|c|c|c|c|}
\hline $\begin{array}{c}\mathbf{H b}_{\mathbf{i}} \\
\%\end{array}$ & $\mathrm{Hb}_{0}$ & $\underset{\text { per }}{\mathbf{S}_{\mathbf{i}}}$ & $\begin{array}{r}S_{\circ} \\
, 000\end{array}$ & $\mathbf{E}_{\mathbf{i}}$ & $\mathrm{E}_{\mathbf{o}}$ & M.C.H.i & M.C.H.o & W.B.C.i & W.B.C.o & $\mathbf{P}_{\mathbf{i}}$ & $\mathrm{L}_{\mathbf{i}}$ & $\mathbf{O}_{\mathbf{i}}$ & $\mathbf{P o}_{\mathbf{0}}$ & Lo & $\mathrm{O}_{\mathbf{o}}$ & $\mathrm{FeSO}_{4}$ \\
\hline $\begin{array}{l}55 \\
74 \\
68 \\
70 \\
53 \\
73 \\
58 \\
73 \\
69 \\
64 \\
46\end{array}$ & \begin{tabular}{|r|}
101 \\
93 \\
110 \\
87 \\
90 \\
90 \\
102 \\
76 \\
97 \\
78 \\
95 \\
48
\end{tabular} & $\begin{array}{r}20 \\
4 \\
19 \\
10 \\
10 \\
14 \\
6 \\
10 \\
6 \\
6 \\
13 \\
17 \\
30\end{array}$ & $\begin{array}{l}4 \\
4 \\
4 \\
8 \\
4 \\
3 \\
6 \\
5 \\
8 \\
5 \\
8\end{array}$ & $\begin{array}{l}3.8 \\
3.9 \\
4.4 \\
3.7 \\
3.5 \\
3.8 \\
3.0 \\
3.8 \\
4.0 \\
3.8 \\
2.7\end{array}$ & $\begin{array}{l}4 \cdot 7 \\
4 \cdot 5 \\
4 \cdot 9 \\
5 \cdot 1 \\
5 \cdot 0 \\
4 \cdot 7 \\
5 \cdot 3 \\
4 \cdot 0 \\
3 \cdot 2 \\
5 \cdot 0 \\
2 \cdot 7\end{array}$ & $\begin{array}{l}21.6 \\
27.9 \\
22.5 \\
28.0 \\
22.1 \\
26.0 \\
28.5 \\
28.0 \\
25.5 \\
25.0 \\
25.0\end{array}$ & $\begin{array}{l}31 \cdot 5 \\
30 \cdot 0 \\
30 \cdot 0 \\
25 \cdot 5 \\
26 \cdot 8 \\
33 \cdot 0 \\
22 \cdot 0 \\
35 \cdot 0 \\
35 \cdot 0 \\
29 \cdot 0 \\
26 \cdot 0\end{array}$ & $\begin{array}{r}10 \cdot 0 \\
7 \cdot 4 \\
8 \cdot 3 \\
14 \cdot 8 \\
9 \cdot 3 \\
7 \cdot 3 \\
7 \cdot 3 \\
10 \cdot 3 \\
11 \cdot 2 \\
10 \cdot 5 \\
5 \cdot 3\end{array}$ & $\begin{array}{r}9 \cdot 5 \\
10 \cdot 2 \\
7 \cdot 4 \\
14 \cdot 2 \\
9 \cdot 4 \\
10 \cdot 0 \\
7 \cdot 4 \\
6 \cdot 0 \\
10 \cdot 9 \\
11 \cdot 7 \\
4 \cdot 8\end{array}$ & $\begin{array}{l}65 \\
70 \\
60 \\
90 \\
55 \\
72 \\
58 \\
60 \\
65 \\
70 \\
50\end{array}$ & $\begin{array}{l}34 \\
28 \\
38 \\
8 \\
45 \\
18 \\
40 \\
38 \\
34 \\
27 \\
48\end{array}$ & $\begin{array}{l}1 \\
2 \\
2 \\
2 \\
0 \\
0 \\
2 \\
2 \\
1 \\
3 \\
2\end{array}$ & $\begin{array}{l}58 \\
65 \\
62 \\
85 \\
60 \\
65 \\
65 \\
70 \\
70 \\
62 \\
55\end{array}$ & $\begin{array}{l}39 \\
34 \\
38 \\
12 \\
38 \\
34 \\
33 \\
28 \\
27 \\
38 \\
45\end{array}$ & $\begin{array}{l}3 \\
1 \\
0 \\
3 \\
2 \\
1 \\
2 \\
2 \\
3 \\
0 \\
0\end{array}$ & 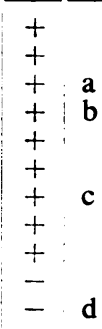 \\
\hline
\end{tabular}

$\mathrm{E}=$ Erythrocytes in $10^{6}$ per c.mm. W.B.C. in $10^{3}$ per c.mm. M.C.H. in $\mu \mu \mathrm{g}$.

$\mathbf{P}=$ Polymorphs $\%$. L = Lymphocytes $\%$. $\quad \mathbf{O}=$ Others $\%$.

$\mathrm{a}=$ Recent history of lead hazard.

$\mathrm{b}=$ Absolute and relative polymorphonuclear leucocytosis.

$c=$ Became very hypochromic histologically.

$\mathrm{d}=$ Suspected of "splenic anaemia."

incidence was $25(=3.8 \%)$ and $2(=0 \cdot 3 \%)$. Of these, 8 and 1 respectively were residua from the original " anaemics," the others having fallen below the critical value during the course.

The " anaemias" were of " simple" type, about half being originally normochromic normocytic, over one-third being hypochromic normocytic, and the remainder hypochromic microcytic. After training, the blood picture was normochromic and normocytic in 79 out of the 93 cases, and hypochromic microcytic in only 3 instances. Anisocytosis and poikilocytosis were rather rare findings.

The white cell picture was remarkably normal in these " anaemics," only one abnormal picture-a relative and absolute neutrophil polymorphonuclear leucocytosis-being found. One case had a rather low total white count. This was the most severe and resistant anaemia of the whole group, and was thought to be a "splenic anaemia." One anaemia was thought to be possibly associated with lead hazard.

Iron deficiency of any marked degree was excluded as an aetiological factor in the production of the "anaemias" by giving adequate therapeutic doses of iron (ferrous sulphate, 9 grains daily for 30 to 50 days) to about one-half of the " anaemics." Apart from a lower coefficient of variation in the treated group, there was no difference in the end-result in the two groups.

Another unexpected finding was that 17 cases who came in with haemoglobin values over $85 \%$, of whom 7 were over $95 \%$ and 3 over $100 \%$, went out with haemoglobin values of less than $86 \%$. It is of considerable interest that 13 of these 17 cases came from the third company, whose differences from the remaining two 
companies have been discussed. A comparison of the observed fall in haemoglobin values and that calculated from the haemoglobin-siderocyte regression coefficients suggests that the factors working on the haematological equilibrium are similar in their quantitative results to those obtaining in the "non-anaemics" before training, rather than to those after training. It seems possible that this technique of residual estimation from a haemoglobin-siderocyte regression holds possibilities in haematological investigations.

A similar analysis of the " hard core" of anaemics suggests that the dynamics of their haematological equilibrium lie between that of the incoming recruits and that of the outgoing ones.

\section{SUMMARY}

A study of the haematological picture of 663 substandard recruits under training has been made, using haemoglobin estimations, siderocyte counts, stained films, and in some cases full blood counts. Many further data, such as social background and family history, were collected during the investigation, but it is outside the scope of this communication to attempt to correlate these, and this discussion is purely haematological in its treatment.

On starting the course the recruits had a rather low (94.5\%) haemoglobin level, with a high proportion (14\%) of values below $86 \%$. After training the mean had risen to $98.7 \%$, and the incidence of low values had fallen to $3.8 \%$. These latter figures are very similar to the figures obtained by the Haemoglobin Survey (M.R.C., 1945) for a random sample of males of the same age.

Not only did the haemoglobin mean rise during training, but the scatter around the mean, expressed as the coefficient of variation, also diminished significantly. At the same time there was a marked tendency for values to converge upon a modal point at the level $97 \cdot 5 \%-102 \cdot 5 \%$. This converging tendency gives rise to a hypothesis that there may be an optimum haemoglobin level associated with the occupational environment.

The siderocyte levels on entrance were raised $(7.8$ per 1,000$)$, but fell to " normal "values $(4 \cdot 7$ per 1,000$)$ after training. There was a high degree of correlation between the siderocyte levels and the haemoglobin levels, and regression coefficients were calculated before and after training. These coefficients were used to calculate the expected behaviour of the haemoglobin values of some groups of recruits, and a possible method of analysing some of the factors affecting haematological equilibrium was developed.

The " anaemias" were investigated and found to be " simple" normochromic normocytic, hypochromic normocytic, or hypochromic microcytic in type. Most of them improved markedly under training, but the administration of ferrous sulphate to about half of them had no effect. However, the diet was not deficient in iron. 


\section{CONCLUSIONS}

1. The haemoglobin levels of substandard recruits sent to a Physical Development Centre were found to be low on arrival (94.5\% "Haldane ") with a rather large coefficient of variation $(10 \%)$.

2. An unexpectedly large number of the recruits (14\%) showed values of less than $86 \%$, being anaemias of " simple type," mainly normochromic normocytic, with some hypochromic normocytic and hypochromic microcytic types.

3. The siderocyte levels of the recruits on arrival were raised $(7 \cdot 8$ per 1,000$)$.

4. After training, the haemoglobin mean had risen to $98.7 \%$ and the coefficient of variation contracted to $7 \cdot 3 \%$. These figures approximate very closely to the Haemoglobin Survey's figures for males of the same age group.

5. After training, the incidence of figures below $86 \%$ had fallen to $3.8 \%$, which is the same as that reported in the Haemoglobin Survey. Some cases (17), mainly from one company, which differed in several respects from the other two, fell from higher levels to below $86 \%$.

6. There was a marked tendency for initially high values to converge upon a mean, suggesting an optimum value for these recruits fitting them for the conditions imposed by the training.

7. The administration of iron as ferrous sulphate was without effect on the " anaemics," a control group improving to exactly the same extent.

8. After training, the siderocyte level had fallen to $4 \cdot 7$ per 1,000 , which is not significantly different from that of males of the same age group.

9. Both before and after training, haemoglobin and siderocyte levels show a high degree of correlation.

Acknowledgments are due to Brigadier Frank Howitt, Army Department of Physical Medicine, Brigadier F. A. E. Crew, F.R.S., and Professor Lancelot Hogben, F.R.S., Army Department of Medical (Statistical) Research, for the planning and execution of the comprehensive scheme, of which these studies form a small part; and I should like to take this opportunity of thanking the many people who so willingly co-operated in implementing the scheme, especially Dr. D. Woodhouse, Cancer Research Department, University of Birmingham, for lending his "Spekker" photoelectric absorptiometer to the unit, Dr. Ewart Jones, County Laboratories, Hereford, for his ungrudging assistance in providing materials on demand; the C.O. and staff of No. 1 P.D.C., Hereford, for being helpful and courteous to the unit during the researches; Mr. Basil Morson for his help with siderocyte counting; and Mr. James Weir, who, as technician, bore the brunt of the active part of the work, and without whose devoted and untiring efforts it would have been impossible to complete the undertaking.

Thanks are also due to Professor G. Haswell Wilson, Department of Pathology, University of Birmingham, and Surgeon Commander C. L. G. Pratt, O.B.E., Medical Officer in Charge of R.N. Physiological Laboratory, for releasing me to collaborate in this research.

\section{REFERENCES}

Case, R. A. M. (1943). Nature, 152, 599.

(1944). J. Physiol., 103, 14P.

(1945a). Nature, 156, 115.

(1945b). Proc. roy. Soc., B. (in the press).

(1945c). J. Path. Bact., 57, 271.

Ladan, V. N., and Nutt, M. E. (1945). Nature, 155, 270. 
Clegg, J. W., and King, E. J. (1942). Brit. med. J., 2, 329.

Committee on Haemoglobin Surveys. M.R.C. Report Series 252 (1945), H.M. Stationery Office, London.

Davidson, L. S. P., Donaldson, G. M. M., Lindsay, S. T., and McSorley, J. G. (1943). Brit. med. J., 2, 95 .

Haldane, J. B. S. (1945a). Nature, 155, 49.

(1945b). Biometrika (in the press).

Haldane, J. S. (1901). J. Physiol., 26, 497.

King, E. J., Gilchrist, M., and Matheson (1944). Brit. med. J., 1, 250.

Macfarlane, R. G., and O'Brien, J. R. P. (1944). Ibid., 1, 248.

"Student" (1908). Biometrika, 6, 1.

Tweedie, M. K. (1945). Nature, 155, 453.

van Slyke, D. D., and Neill, J. M. (1924). J. biol. Chem., 61, 523.

\section{GENERAL ADVISORY BOARD}

The Editors of the British Journal of Social Medicine are anxious to keep in close touch with centres of social medicine in other parts of the world. To this end they are forming a General Advisory Board. Up to the time of going to press for the first issue, not all those so far invited to serve on the Board have replied. It is hoped to print a full list in the second issue. Meantime the Editors note with pleasure that the following have expressed their willingness to serve:

Dr. L. Derobert (Archives de Médecine Sociale, Paris).

Prof. Gunnar Dahlberg (Swedish State Institute for Human Genetics and Race Biology).

Prof. Elena Fambri (Institute of Social Medicine, Rome).

Prof. M. Kacprzak (Government School of Hygiene, Warsaw).

Prof. J. Leclercq (Institute of Forensic and Social Medicine, University of Lille).

Dr. V. J. Prosek (Institute of Social Medicine, Charles University, Prague).

Prof. J. G. Remijnse (Institute of Social Medicine, University of Utrecht).

Prof. Knud Sand (President of the International Academy of Forensic and Social Medicine; Institute of Social Medicine, Copenhagen).

Prof. Réné Sand (Institute of Social Medicine, University of Brussels).

Dr. Henry E. Sigerist (Institute of the History of Medicine, The Johns Hopkins University, Baltimore).

Dr. A. Stampar (Department of Public Health and Social Medicine, Zagreb University, Yugoslavia). 